\title{
Prevalence of orofacial alterations in sickle cell disease: a review of literature
}

\author{
Poliana Ramos Braga Santos', Paula Dioné Casais e Silva Machado², Cristina Pinho Passos ${ }^{3}$, \\ Marcio Cajazeira Aguiar ${ }^{4}$, Roberto José Meyer Nascimento ${ }^{5}$, Maria Isabela Guimarães Campos ${ }^{4}$
}

'Dental School, Federal University of Bahia, Salvador, BA, Brazil

${ }^{2}$ Medical School, Federal University of Bahia, Salvador, BA, Brazil

${ }^{3}$ Institute of Health Science, Federal University of Bahia, Salvador, BA, Brazil

${ }^{4}$ Department of Biomorphology, Institute of Health Science, Federal University of Bahia, Salvador, BA, Brazil

${ }^{5}$ Department of Biointeraction, Institute of Health Science, Federal University of Bahia, Salvador, BA, Brazil

Received for publication: May 07, 2013 Accepted: September 17, 2013

Correspondence to: Marcio Cajazeira Aguiar Instituto de Ciências da Saúde Departamento de Biomorfologia Av. Reitor Miguel Calmon, $\mathrm{s} / \mathrm{n}^{\circ}$ Vale do Canela, CEP: 40.110-902, Salvador, BA, Brasil

Phone: +557132838888

Fax: +557132838884

E-mail: mcaguiar@ufba.br

\begin{abstract}
Aim: To evaluate the manifestations of sickle cell disease on the orofacial complex through a review of current literature concerning prevalence of dental caries, periodontal disease, temporomandibular joint disorders and radiographic alterations of maxillofacial bones. Methods: Full-text papers retrieved from MEDLINE and LILACS electronic databases were critically reviewed. Results: Alterations of maxillofacial bones are well documented in the literature, but studies reporting caries, periodontal condition and temporomandibular joint alterations in are scarce and inconclusive. Conclusion: Further well-designed epidemiological studies are needed to indicate the real impact of this disease on the stomatognathic health, collaborating to improve public health policies.
\end{abstract}

Keywords: sickle cell anemia, hemoglobin $\mathrm{C}$ disease, dental caries, periodontal diseases, temporomandibular joint, diagnostic X-ray.

\section{Introduction}

Sickle cell disease (SCD) includes genetic blood disorders in which morphologic alterations of erythrocytes are caused by presence of the sickle hemoglobin $(\mathrm{HbS}) . \mathrm{HbS}$ is characterized by a mutation in the sixth position of $\hat{a}$ globulin chain, replacing the glutamic acid by valine ${ }^{1-3}$. Sickle cell anemia (SCA) is the most common and severe form of SCD, resulting from genetic inheritance of $\mathrm{HbS}$ genes from both progenitors (SS genotype) ${ }^{1}$. The SC disease is the most second common manifestation of SCD, presenting less severe symptoms ${ }^{4}$, and is characterized by heterozygosis of two mutant hemoglobins, $\mathrm{HbS}$ and $\mathrm{HbC}$ ( $\mathrm{SC}$ genotype). In sickle cell trace, the heterozygosis for genes of normal ( $\mathrm{HbA})$ and mutant (HbS) hemoglobins (AS genotype) does not exhibit clinical symptoms of the disease under physiological conditions $\mathrm{s}^{3,5}$.

SCD can be found in several countries affecting people all over the world, but primarily affects African descendents ${ }^{5}$. In Brazil, it's estimated the existence of more than 2 million carriers of the gene for $\mathrm{HbS}$, with 700 to 1000 new cases of SCD every year, turning such disorder into a public health problem ${ }^{6}$. 
The sickle erythrocyte presents reduced flexibility and becomes more adherent to vascular endothelium, developing vaso-occlusion of microvasculature and subsequent local hypoxia ${ }^{1,7}$. Premature destruction of sickle red blood cells leads to hemolytic anemia. These mechanisms are the mean hallmarks of SCD and are responsible for its clinical manifestations ${ }^{1,8}$.

Algic crises is the most common and important clinical symptom of this disease 9 . Several other complications have been described, including: stroke, pulmonary infarct with decreased lung function, priapism, chronic renal failure, splenic and hepatic dysfunctions, jaundice, retinal ischemia causing transient or permanent blindness, chronic leg ulceration, apathy, cardiac alterations, convulsion and osseous alterations like osteonecrosis, osteomyelitis, osteopenia and osteoporosis, 40,11 . It is noted a wide interindividual variety of disease severity that has been suggested as result of polymorphisms in several genes ${ }^{12}$, mainly of fetal hemoglobin which has been pointed as a target for promising treatments ${ }^{13}$.

Little research has been done on the possible impact of this disease in the stomatognathic health. The aim of this paper was to review the literature regarding the actual knowledge concerning orofacial conditions in patients with SCD.

\section{Dental Caries}

There are few studies in the literature concerning prevalence of caries lesions in SCD patients and even those presented controversial results.

In 1986, Okafor et al. ${ }^{14}$ found a reduced caries prevalence (35.13\%) among 37 SCD adult patients (14-33 years old) when compared to 20 control subjects $(54 \%)$ paired by age and gender. This finding was attributed to a reduced ingestion of sweets but its methodology was not specified in details, neither statistic comparisons were presented.

In a retrospective study, no statistically significant difference was observed in the prevalence of dental caries determined by DMFS index between $35 \mathrm{HbSS}$ subjects and 140 control volunteers, both under treatment at a dental school and frequency matched on enrollment period and age. However, the great age variability among volunteers (5-92 years old) in this study may have influenced its results ${ }^{15}$.

The controversial results can be related to socioeconomic factors that may influence caries risk rather than the hematologic disorder itself ${ }^{16,17}$. Comparing DMFS index of 102 sickle subjects $(82 \mathrm{HbSS}, 15 \mathrm{HbSC}$ and $5 \mathrm{HbS}$ betathalassemic) and 103 control volunteers between 18 and 70 years old, the statistical analysis, adjusted for SCD severity, age, gender, risk factors for caries and socioeconomic data, demonstrated that for low-income African Americans, those with SCD presented significantly more decayed and fewer filled surfaces ${ }^{18}$. Since control volunteers were selected at dental colleges, these findings should be considered with regards.

Reduced prevalence of decayed teeth was also reported among $60 \mathrm{HbSS}$ children when compared to a control group paired by age and race. Prolonged use of penicillin by falcemic children prevents acquisition of Streptococcus mutans, reflecting the significant reduction in dental caries in these individuals ${ }^{19}$.
In the SCD patients, risk factors for caries seem to be similar to that observed in healthy subjects. Passos et al. ${ }^{20}$ (2012) investigated the prevalence of dental caries and periodontal condition in 99 subjects with SCD and a control group comprising 91 without disease, analyzing some associations with disease severity. Their findings suggested that the sickle condition or the disease's clinical severity were not the main risk factors for the development of caries and periodontal disease. In this study, older age, female gender and daily smoking proved to be more important risk factors for higher Decayed, Missing and Filled Teeth index (DMFT). Their data suggested that risk factors known to affect the occurrence of dental caries were more important than SCD on the dental condition of subjects with SCD.

\section{Periodontal Conditions}

It has been reported that hygiene and oral care are important factors that influence the severity of periodontal disease and can prevent complications and infections in patients with $\mathrm{SCA}^{17,21}$

A case report of a 14-year-old boy, during his ninth episode of sickle cell crisis, described an unusual complication, characterized by swelling on the right side of the face without any infection related. Gingival enlargement, firm to palpation, was found in the lower arch on both sides. Biopsies suggested that gingival edema was a result from repeated hemorrhage episodes followed by fibrous tissue repair formation ${ }^{22}$.

Crawford $^{23}$ (1988), evaluating clinical and radiographically 78 African patients with SCA, SC disease or thalassemia, did not observe significant association between SCD and gingivitis or periodontitis when compared to control group. The authors believe that in a larger population, in which more severe cases of SCD could be reached, periodontal disease might be affected by SCD.

Arowojolu et al..$^{24}$ (1997), through a prospective comparative study over 6 months, analyzed gingival and plaque indexes and probing depths in $50 \mathrm{SCA}$ patients and 50 normal ones (11-19 years). No significant differences were found when groups were compared, suggesting that SCA did not lead to increased periodontal disease. Additionally, statistical significant difference was observed in probing depths only when female patients were considered (2.71 and $2.06 \mathrm{~mm}$, for SCA and controls, respectively). Even though probing depths until $3 \mathrm{~mm}$ are accepted as normal, it was suggested that these findings might be of clinical importance with advancing age ${ }^{21}$.

The same results were observed by Guzeldemir et al. ${ }^{25}$ (2011). They evaluated 55 SCD patients and observed that there was no difference regarding the periodontal disease between SCD patients and healthy subjects. The authors were unable to assert that the disease could be a risk factor for periodontal disease.

According to most of literature available, SCD does not appear to predispose to periodontal complications. Passos et $a l^{20}$ (2012) did not observe association between SCA and periodontal disease in SCD patients. Their study showed that 
higher risk for periodontal pockets was associated with older age and the absence of daily use of dental floss, which are recognized as risk factors for periodontal disease. Nevertheless, new investigations should be performed in order to assess the role of periodontal infection in the worsening of SCD picture, initiating or exacerbating vasoocclusive episodes.

\section{Temporomandibular joint (TMJ) disorders}

SCD patients are commonly affected by bone and joint complications. The most common area of bone destruction is the femoral head, but other regions have been described: humeral head, thoracic and lumbar spine and temporomandibular joint $(\mathrm{TMJ})^{26}$.

There are few papers in the literature about TMJ disorders in $\mathrm{SCD}$, all reporting clinical cases. It was reported a clinical case of a 23 years old Saudi female with SCA that early demonstrated signs of bony infarction of humeral head and avascular necrosis of TMJ and head femur, all in the left side, diagnosed by clinical examination and computed tomography. The authors suggested that despite the protective mechanisms of TMJ, it was not absolutely immune against vaso-occlusive episodes of SCA nature ${ }^{27}$.

Another case of TMJ disorder was reported in a 23year-old woman with SCA, who presented no trauma history or orthognathic surgery. During clinical examination, it was observed limited mouth opening, central line deviation to the right side and a slight facial asymmetry because of the short right ramus height. A flattened condyle and avascular necrosis of glenoid fossa were demonstrated on the right joint through radiological examination and computed tomography. Authors suggested that subtle onset of TMD symptoms should been taken seriously, especially in SCA adolescents (11 to 15 years), when bone changes become more obviously. Prevention of overloading and conservative approaches can prevent the development of irreversible deformities of $\mathrm{TMJ}^{28}$.

Caracas et al. ${ }^{29}$ (2013) reported a rare case of aseptic arthritis in the TMJ of a 22-year-old woman with SCA. The patient experienced pain in the left preauricular region, hyperalgesia of the left masseter muscle, mouth opening limitation and mild edema. Aseptic arthritis in the left condylar head secondary to a sickle cell crisis was diagnosed after the evaluation of the laboratory tests and images. The treatment consisted parenteral opioid analgesia and nonsteroidal anti-inflammatory drugs for manage of intense pain and blood transfusion because of severe anemia. Health professionals should be aware that aseptic arthritis may also be provoked by SCD. Laboratory tests and diagnostic imaging are important for differential diagnosis.

\section{Radiographic Alterations}

SCD patients usually present common radiographic features due to lesions in the cortical bone and bone marrow, often affecting the maxillofacial area ${ }^{30}$. Maxillary bone alterations in SCD are classified as: (1) lesions with osteoporotic appearance due to bone marrow hyperplasia,
(2) radiopaque images associated to vaso-occlusive phenomena and (3) osteomyelitis lesions due to infections. All these maxillofacial features are similar to the ones found in the rest of the skeleton ${ }^{31}$.

Hemolytic anemia in SCD patients promotes a compensatory marrow hyperplasia resulting in trabecular bone changes associated with expansion of the jaws ${ }^{28}$. Enlarged bone marrow spaces usually appear as radiolucent areas between the root apices of posterior teeth and in the inferior border of the mandible, creating in some cases a horizontal trabecular pattern described as "step-ladder"

Demirbas et $a l^{32}$ (2004) reported decreased trabecular bone density and enlarged bone marrow spaces in $67 \%$ of 36 SCA patients. However, "stepladder trabecular" pattern was observed in only $28 \%$ of these patients. Faber et al. ${ }^{33}$ (2002) evaluated intertrabecular spacing in periapical digital radiographs from 18 SCA patients and control volunteers (mean age 20.8 years). Significant increase of intertrabecular spacing in both jaws and reduction of trabecular complexity were noted in SCA individuals. Demirbas et al. ${ }^{34}$ (2008) investigated trabecular bone complexity of posterior mandible in $35 \mathrm{SCA}$ patients (age ranged 11 to 40 years) and 26 control individuals using fractal dimension analysis from panoramic radiographs. SCA patients under age 20 showed significant lower fractal dimension values, pointing to scarcity of trabecular bone, when compared to control individuals.

Neves et al. ${ }^{35}$ (2011) used panoramic radiograph to evaluate the radiographic features in the oral and maxillofacial region in Brazilian patients with SCD and healthy subjects. The healthy group showed a significantly smaller number of radiographic alterations when compared to the SCD patients. Increased intertrabecular distance, decreased trabecular complexity and the absence of mandibular canal corticalization were observed in subjects with HbSS. These findings were statistically significant when compared to the control group. The alterations of the trabecular pattern may be related to presence of hemolytic anemia in subjects with SC. Theses alterations may be found in healthy patients, but the occurrence of increased spacing of bone trabecular is more common between patients with SCD. These data provide important information for identifying the disease.

Bone marrow expansion promotes maxilla overgrowth, which can increase the distance between upper and lower incisors teeth, resulting in altered interlabial distance with an untoward physical appearance and occlusion problems ${ }^{36}$. Brown et al. ${ }^{37}$ (1986), analyzing lateral skull radiographs of 50 SCA patients and 25 control volunteers matched by age and gender, observed in the first group a significant difference in maxillary protrusion due to increase in palate-alveolarridge angle. Licciardello et al. ${ }^{36}$ (2007) evaluated cephalometric radiographs from 36 patients with and 36 control volunteers (18.5-51 years). Patients with SCD presented a significantly maxillary incisor proclination and protrusion of the lower and upper lip. However the most severe craniofacial changes occurred in SS patients when compared to thalassemic ones.

A less frequently radiographic finding is the expansion 
of bone marrow in the calvarium, which is more often observed in very young patients. The widening of the diploe narrows the outer table, while perpendicular orientation of trabeculae to inner table gives a "hair-on-end" or "bristlelike" appearance ${ }^{30,31}$.

Radiopaque lesions presented by SCD patients are commonly associated to bone infarction and osteonecrosis ${ }^{30-}$ ${ }^{31}$. In the first situation, long bones are affected more often, yet osteonecrosis usually takes place in articular surfaces ${ }^{38}$. It is suggested that the mandibular posterior region is the most affected by these lesions, coinciding with severe facial pain during sickle cell crisis. The affected area is ischemic and aseptic. Initially the decalcification is surrounded by reactive sclerosis and later it is separated from cortex by a thinning radiolucent area, characterizing a "bone-withinbone" appearance ${ }^{31}$.

Kavadia-Tsatala et al. ${ }^{31}$ (2004), evaluating panoramic and cephalometric radiographs, found radiopaque lesions associated to bone infarct in 6 of 42 SCD patients (20-65 years old). Lesions were related to vaso-occlusive phenomena, since it was followed by a painful crises episode and without any dental pathology associated. Podlesh et al..$^{39}$ (1995) reported a case of an 21 years-old man, hospitalized during a sickle cell crisis, who presented a profound anesthesia of the right mental nerve, fever, acute pain and tenderness to palpation on the right mandible. Laboratory data showed no evidence of infection, however scans revealed cortical bone and bone marrow infarction of the right mandible. Hamdoun et al $^{40}(2012)$ reported a case of an 15 -year-old boy who showed no sensation to pain or touch of the entire lower lip and chin. The finding by magnetic resonance imaging were consistent with bone infartion. This case is considered unique because the patient was a child and had bilateral mental neuropathy. Moreover, patients with SCD are more likely to report pain than a lack of sensitivity. It is possible that frequency of complications such mental nerve neuropathy in patients with SCA be high. Mendes et $a l^{41}$ (2011), comparing the prevalence of oral manifestations in 330 patients comprising subjects with SCA and clinically normal patients, observed that the prevalence of previous mental nerve neuropathy in patients with SCA was 2.2 times greater than observed in individuals without the disease, particularly in the female.

Osteomyelitis occurs up to 200 times more frequently in SCD subjects than in the rest of population ${ }^{38,42}$. It is suggested that bone infarcts are the initial incident. The infarcted area is a propitious environment for bacteria growth, especially Salmonella and Staphylococcus aureus that migrate from several sources ${ }^{38,43}$. Mandibular osteomyelitis seems to develop from direct extension of periapical abscess ${ }^{38}$ or pericoronitis ${ }^{43}$ and displays the same signs of bone infarcts like pain, soft tissue swelling, fever and leukocytosis ${ }^{39}$. Differential diagnosis between infarction and osteomyelitis can be very difficult, however this distinction is important as these two bone lesions are treated differently ${ }^{44}$. Magnetic resonance imaging was suggested to be useful to investigate these lesions. However, only techniques able to identify the infectious organism are reliable to establish a correct verdict ${ }^{42}$.

\section{Final Considerations}

Considering the currently available literature, radiographic alterations of orofacial bones are better documented, while there is no precise knowledge concerning the prevalence and impact of caries, periodontal condition and TMD in the SCD.

It seems like orofacial complications depends not only on the presence of sickle disease, but also on factors related to the subject such as oral hygiene, diet habits and social conditions. Although there is no direct association between SCD and orofacial problems, limitations from systemic complications of this disease can reduce the patient's availability for dental care. A poor buccal condition can act as an infectious focus for vasoocclusive crisis precipitation, compromising even more health and social life of these individuals.

Further well-designed epidemiological studies are needed to understand and recognize oral manifestations related with SCD, indicating the real impact of this disease on stomatognathic health and collaborating to improve public health policies.

\section{References}

1. Steinberg MH. Pathophysiology of sickle cell disease. Baillieres Clin Haematol. 1998;11:163-184.

2. da Fonseca M, Oueis HS, Casamassimo PS. Sickle cell anemia: a review for the pediatric dentist. Pediatr Dent. 2007;29:159-69.

3. Pauling L, Itano HA, Singer SJ, Wells, IC. Sickle cell anemia a molecular disease. Science. 1949;110:543-8.

4. Nagel RL, Fabry ME, Steinberg MH. The paradox of hemoglobin SC disease. Blood Rev. 2003;17:167-178.

5. Creary M, Williamson D, Kulkarni R. Sickle cell disease: current activities, public health implications, and future directions. J Womens Health (Larchmt) 2007; $16: 575-82$

6. Ministry of Health. Secretary of Attention to Health. Manual of Oral Health in sickle cell disease. Brasilia: Ministry of Health, 2005. 52 p.

7. StuartMJ, Nagel RL. Sickle-cell disease. Lancet. 2004;364:1343-60.

8. Kelleher M, Bishop K, Briggs P. Oral complications associated with sickle cell anemia: a review and case report. Oral Surg Oral Med Oral Pathol Oral Radiol Endod. 1996;82:225-8.

9. Ramakrishna Y. Dental considerations in the management of children suffering from sickle cell disease: a case report. J Indian Soc Pedod Prev Dent. 2007;25:140-3.

10. Serjeant GR. Sickle-cell disease. Lancet. 1997;350:725-30.

11. Kato GJ, Gladwin MT, Steinberg MH. Deconstructing sickle cell disease: Reappraisalof the role of hemolysis in the development of clinical subphenotypes. Blood Rev. 2007;21:37-47.

12. Steinberg $\mathrm{MH}$, Adewoye $\mathrm{AH}$. Modifier genes and sickle cell anemia. Curr Opin Hematol. 2006;13:131-136.

13. Orkin SH, Higgs DR. Sickle cell disease at 100 years. Science. 2010;329:291-292.

14. Okafor LA, Nonnoo DC, Ojehanon PI, Aikhionbare O. Oral and dental complications of sickle cell disease in Nigerians. Angiology. 1986;37:672-5.

15. Laurence B, Reid BC, Katz RV. Sickle cell anemia and dental caries: a literature review and pilot study. Spec Care Dentist. 2002;22:70-4.

16. Luna AC, Rodrigues MJ, Menezes VA, Marques KM, Santos FA. Caries prevalence and socioeconomic factors in children with sickle cell anemia. Braz Oral Res. 2012; 26:43-9.

17. Javed F, Correa FO, Nooh N, Almas K, Romanos GE, Al-Hezaimi K. Orofacial manifestations in patients with sickle cell disease. Am J Med Sci. 2013;345:234-7. 
18. Laurence B, George D, Woods D, et al. The association between sickle cell disease and dental caries in African Americans. Spec Care Dentist. 2006;26:95-100.

19. Fukuda JT, Sonis AL, Platt OS, Kurth S. Acquisition of mutans streptococci and caries prevalence in pediatric sickle cell anemia patients receiving long-term antibiotic therapy. Pediatr Dent. 2005;27:186-90.

20. Passos CP, Santos, PRB, Aguiar MC, Cangussu MCT, Toralles MBP, da Silva M C BO, Nascimento RJM, Campos MI G. Sickle cell disease does not predispose to caries or periodontal disease. Special Care in Dentistry. 2012;32:55-60.

21. Arowojolu MO. Periodontal probing depths of adolescent sickle cell anaemic (SCA) Nigerians. J Periodontal. Res 1999;34:62-4.22.

22. Scipio JE, Al-Bayaty HF, Murti PR, Matthews R. Facial swelling and gingival enlargement in a patient with sickle cell disease. Oral Dis. 2001;7:306-9.

23. Crawford JM. Periodontal disease in sickle cell disease subjects. $\mathrm{J}$ Periodontol. 1988;59:164-9.

24. Arowojolu MO, Savage KO. Alveolar bone patterns in sickle cell anemia and non-sickle cell anemia adolescent Nigerians: a comparative study. J Periodontol. 1997;68:225-8.

25. Guzeldemir E, Toygar HU, Boga C, Cilasun U. Dental and periodontal health status of subjects with sickle cell disease. Journal of Dental Sciences. 2011;6:227-234

26. Aguilar C, Vichinsky E, Neumayr L. Bone and joint disease in sickle cell disease. Hematol Oncol Clin North Am. 2005;19:929-41.

27. el-Sabbagh AM, Kamel M. Avascular necrosis of temporomandibular joint in sickle cell disease. Clin Rheumatol. 1989;8:393-7.

28. Baykul T, Aydin MA, Nasir S. Avascular necrosis of the mandibular condyle causing fibrous ankylosis of the temporomandibular joint in sickle cell anemia. J Craniofac Surg. 2004;15:1052-6.

29. Caracas Mda S, Jales SP, Jales Neto LH, da Silva Castro JC, Suganuma LM, Fonseca GH, Gualandro SF, de Siqueira JT. Temporomandibular joint arthritis in sickle cell disease: a case report. Oral Surg Oral Med Oral Pathol Oral Radiol. 2013 Feb;115(2):e31-5.30.

30. Yanaguizawa M, Taberner GS, Cardoso FNC, Natour J, Fernandes ARC. Diagnóstico por Imagem na Avaliação da Anemia Falciforme. Rev Bras Reumatol. 2008;48:102-5.

31. Kavadia-Tsatala S, Kolokytha O, Kaklamanos EG, Antoniades K, Chasapopoulou E. Mandibular lesions of vasoocclusive origin in sickle cell hemoglobinopathy. Odontology. 2004;92:68-72.

32. Demirbas AK, Aktener BO, Unsal C. Pulpal necrosis with sickle cell anaemia. Int Endod J. 2004;37:602-6.

33. Faber TD, Yoon DC, White SC. Fourier analysis reveals increased trabecular spacing in sickle cell anemia. J Dent Res. 2002;81:214-8.

34. Demirbas AK, Ergun S, Guneri P, Aktener BO, Boyacioglu H. Mandibular bone changes in sickle cell anemia: fractal analysis. Oral Surg Oral Med Oral Pathol Oral Radiol Endod. 2008;106:e41-8.

35. Neves FS, de Almeida DA, Oliveira-Santos C, dos Santos JN, Toralles MB, da Silva MC, Campos MI, Crusoé-Rebello I. Radiographic changes of the jaws in $\mathrm{HbSS}$ and $\mathrm{HbSC}$ genotypes of sickle cell disease. Spec Care Dentist. 2011 Jul-Aug;31(4):129-33

36. Licciardello V, Bertuna G, Samperi P. Craniofacial morphology in patients with sickle cell disease: a cephalometric analysis. Eur J Orthod. 2007;29:238-42.

37. Brown DL, Sebes Jl. Sickle cell gnathopathy: radiologic assessment. Oral Surg Oral Med Oral Pathol. 1986;61:653-6.

38. Lawrenz DR. Sickle cell disease: a review and update of current therapy. J Oral Maxillofac Surg. 1999;57:171-8.

39. Podlesh SW, Boyden DK. Diagnosis of acute bone/bone marrow infarction of the mandible in sickle hemoglobinopathy. Report of a case. Oral Surg Oral Med Oral Pathol Oral Radiol Endod. 1996;81:547-9.

40. Hamdoun E, Davis L, McCrary SJ, Eklund NP, Evans OB. Bilateral mental nerve neuropathy in an adolescent during sickle cell crises. J Child Neurol. 2012;27:1038-41.
41. Mendes PH, Fonseca NG, Martelli DR, Bonan PR, de Almeida LK, de Melo LA, Martelli H Jr. Orofacial manifestations in patients with sickle cell anemia. Quintessence Int. 2011;42:701-9.

42. Anand AJ, Glatt AE. Salmonella osteomyelitis and arthritis in sickle cell disease. Semin Arthritis Rheum. 1994;24:211-21.

43. Olaitan AA, Amuda JT, Adekeye EO. Osteomyelitis of the mandible in sickle cell disease. Br J Oral Maxillofac Surg. 1997;35:190-2.

44. Royal JE, Harris VJ, Sansi PK. Facial bone infarcts in sickle cell syndromes. Radiology. 1988;169:529-31. 